\title{
Correlation between Religious Attitude and Resiliency of Women under Domestic Violence
}

\author{
Elham-Sadat Dehghani-Firoozabadi ${ }^{1}$, Jamileh Mohtashami ${ }^{2}$, Foroozan Atashzadeh-Shoorideh ${ }^{3}$, Maliheh Nasiri ${ }^{4}$, \\ Mahrokh Dolatian ${ }^{5} \&$ Sara Sedghi $^{6}$ \\ ${ }^{1}$ Student Research Committee, School of Nursing \& Midwifery, Shahid Beheshti University of Medical Sciences, \\ Tehran, Iran \\ ${ }^{2}$ Psychiatric Nursing Department, School of Nursing \& Midwifery, Shahid Beheshti University of Medical \\ Sciences, Tehran, Iran \\ ${ }^{3}$ Department of Nursing Management, School of Nursing \& Midwifery School, Shahid Beheshti University of \\ Medical Sciences, Tehran, Iran \\ ${ }^{4}$ Department of Midwifery, Faculty of Nursing and Midwifery, Shahid Beheshti University of Medical Sciences, \\ Tehran, Iran \\ ${ }^{5}$ Midwifery \& Health Department, School of Nursing \& Midwifery, Shahid Beheshti University of Medical \\ Sciences, Tehran, Iran \\ ${ }^{6}$ Management of Psychiatric Nursing, Faculty of Nursing \& Midwifery, Shahid Beheshti University of Medical \\ Sciences, Tehran, Iran \\ Correspondence: Jamileh Mohtashami, Vali-Asr Avenue, Cross of Vali-Asr and Neiaiesh Highway, Opposite to \\ Rajaee Heart Hospital, Post Code: 1996835119, Tehran, Iran. Tel: 98-91-2279-7922. Fax: 98-21-8820-2521. \\ E-mail: J_mohtashami@sbmu.ac.ir
}

Received: May 6, 2016 Accepted: June 27, 2016 Online Published: July 21, 2016

doi:10.5539/gjhs.v9n3p199 URL: http://dx.doi.org/10.5539/gjhs.v9n3p199

\begin{abstract}
The most common type of violence against women is domestic violence so that it is considered as a general health crisis. Resilience is a self-healing method featured with positive emotional outcomes. Religious attitudes are of the probable grounds of development of resilience techniques among women who have been victim of domestic violence. The present study is aimed at determining correlation between religious attitudes and resilience among women with domestic violence. The present study is a descriptive correlative research. Selected Health centers in east and north districts of Tehran affiliated with Shahid Beheshti University of Medical Sciences. Data gathering tools were a demographic information questionnaire, Connor-Davidson's Resilience scale, and Serajzadeh's "Muslim Religiosity questionnaire".

We used Pearson correlation test to indicate the presence of correlation between resiliency and religious attitudes. Data analyses were performed in SPSS 16. Mean and standard deviation of religious attitudes and resilience among the women with domestic violence were $76.41 \pm 9.96,68.46 \pm 15.68$ respectively. The results showed that there was correlation between religious attitude and resilience among women who have been subject to domestic violence. $(\mathrm{P}<0.001, \mathrm{r}=0.24)$. Women under domestic violence had stronger religions attitudes and higher resilience strength. It appears that resilience among women subject to domestic violence and the effective factors on resilience and religious attitudes in particular (given the role of religion in Iranians' lives) deserve special attention.
\end{abstract}

Keywords: women, domestic violence, religious attitudes, resilience

\section{Introduction}

The most common type of violence against women is domestic violence or intimate partner violence (Soleiman Ekhtiari \& Ahmadi, 2011) in marriage, dating relationship or cohabitation (Alokan, 2013). Domestic violence includes various aspects such as physical violence, mental violence, sexual violence (Aghakhani, Eftekhari, Zare Kheirabad, \& Mousavi, 2012). Domestic violence is considered as a general health crisis with considerable physical and mental negative effects (Perez, Johnson, \& Wright, 2012). The importance of this issue to the extent that UN General Assembly, declared the 25th of November, the International Day for the Elimination of 
Violence against Women, in 1999. Domestic violence is considered a stressor, which affects the health and function of one person and leads to considerable health problems and decrease quality of life (Bauman, Haaga, Kaltman, \& Dutton, 2012). Violence and the tension associated with it, affects the Immune system and the continuance of it results in mental and physical issues (Dolatian, Hesamy, Zahiroddin, Velaie, \& Alavi Majd, 2011). Murders that occur in connection with domestic violence, are just the tip of the iceberg in comparison with the adverse effects these kind of violence leaves (Davis, 2010).

\subsection{Literatyre Review}

Researches findings indicate 66 percent of Iranian women and 70 percent of women in Tehran experienced violence at least once from their early stage of their relationship (Sadeghi Fsayy, 2011). 18 percent of all Forensic medical centers' clients in Tehran are victims of domestic violence (Mohtashami, Yaghmaei, Jafari, Alavi Majd, \& Ahmadi, 2014).

A study in USA, shows women who experience violence do not want this violence to be identified, even $1 / 3$ of these women do not prefer to be questioned about this matter (Vosoogh \& Forouzesh, 2013). Several number of domestic violence's victims, are trapped in their mental beliefs (Payne \& Wermeling, 2009). Dependency on the victims of violence are common attributes, however those who left their husbands, are 75 percent more likely to be killed by their husband than, those who stayed and never leave their home (Kaplan \& Sadok, 2007).

Statistics reflect the fact that, nearly 90 percent of women under domestic violence won't leave their husbands (Frias, 2013). These women choose one of dysfunctional, Emotional and Problem-focused coping styles. Copping is an effort to overcome the tension and increase efficient solutions to meet the challenges, which includes three components: Concept of the challenging situation, appropriate course of action (problem-solving) and powerful emotional abilities (Faramarzi, Abedi, \& Karimi, 2013).

Some researchers believe, positive emotions, are very important psychological resources, which help individuals to use effective coping methods (SeyedMahmoudi, Rahimi, \& Mohamadi, 2011). Positive emotions, increases active efforts to confront the tension and can improve the idea of how successful these efforts are. This hypothesis has been proposed that positive emotions are linked with resiliency because it developed the accessible collections of thoughts and actions of an individual, in stressful situation. Therefore, having more resilient thinking and positive emotion, increases the individuals coping during the confrontation the tension (Shafieezadeh, 2012).

Resiliency is a self- restoration, which is associated with positive emotional, affection and cognitional outcomes (Hussein Qomi \& Salimi Bejestani, 2012). Resiliency does not mean that an individual is immune against tension; but also return to pervious stat, adaptability and procreator of recovering health in a short period of time (Jain, Buka, Subramanian, \& Molnar, 2012).

Resiliency is the ability of self-adaptation against stressors such as threats, incidences, personal and family problems, health and financial issues (Basim \& Cetin, 2011). Resiliency is a successful process of capability and adaptability despite threatening situation. It is not just passive resistance in the face of damages and threatening situations; but also a resilient individual is an active participant and a producer his/hers surroundings. Resiliency is individual's return to the basic or even higher level of balance (Jowkar \& Noorafshan, 2013).

There are few studies regarding the contributory resiliency resources in improving psychiatric trauma (Seyed Mahmoudi, Rahimi, \& Mohamadi, 2011). One of effective individual factors in resiliency is beliefs system including positive point of view of life, the sense of purposefulness and self- effectiveness. Spirituality is a factor, which during adverse situations increases the adaptation and it can develop the concept and purpose of life (Benzies \& Mychasiuk, 2009). The major function of religion is to create meaning in life; religion gives individuals sense of meaning and connection to the ultimate truth (zahed-babelan, rezaei jamaloei\& Sobhani-Herfati (2012). Religion, have a significant role in coping with negative events of life, and can predict the physical and mental health (Rajabi, Saremi, \& Hossein Bayazi, 2012). Religion can improve mental health and coping with stress through life with the improvement of self-esteem (Chiswick \& Mirtcheva, 2013). Domestic violence could lead to various problems such as depression, post-traumatic stress disorder, substance abuse, homicide or suicide (Coker, Smith, Whitaker, Crawford, \& Flerx, 2012), and improvement of resiliency will decrease delinquency, Alcohol abuse and substance abuse (Zolkoski \& Bullock, 2012).

Researches indicate women have the ability to pass domestic violence; but evidence, which related the way they succeed in this matter, is few. In fact, there is inadequate information regarding strengths and resources, which are used by women under domestic violence to empower them (Anderson, Renner, \& Danis, 2012). The aim of this study was determining correlation between religious attitudes and resilience among women with domestic 
violence.

\section{Methods}

The present study is a correlative research. Selected Health centers in east and north districts of Tehran affiliated with Shahid Beheshti University of Medical Sciences. Candidate who met the inclusion criteria were selected. Data gathering tools were demographic information questionnaire, Connor-Davidson's Resilience scale, and Serajzadeh's "Muslim Religiosity questionnaire".

\subsection{Data Analysis}

Pearson correlation test was used to indicate the presence of correlation between resiliency and religious attitudes Data analyses were performed in SPSS 16.

\subsection{Measuring Tools}

Data gathering tool in this study is a questionnaire consists of four sections: First section, demographic information, including age, number of children, marriage status, occupation, incomings, history of harassment and violence in childhood, duration of violence, agreement on marriage and alcohol, substance, and psychotropic drugs abuse and smoking by individual under violence. In a pilot study, items such as alcohol, substance abuse, smoking in women, nationality, referral to Forensics centers and pregnancy were added to the demographic data.

Second section included Connor-Davidson's Resilience scale. This scale has 25 items and 5 factor such as: Individual merit ( 8 items), trusting the instincts and bearing the negative emotions ( 7 items), positive acceptance of change and having safe relationships (5 items), control (3 items) and spirituality (2 items); and in the five-point Likert scale scored between 0 to 4 (from always correct to completely incorrect). Question related to the first factor included: phrase 24, 12, 11, 25, 10, 23, 17 and 16; second factor included phrase 20, 18, 15, 6, 7, 19 and 14; their factor included phrase 1, 4, 5, 2, and 8; forth factor included phrase 22, 13, and 21and finally fifth factor included phrase 3 and 9. Minimum score of resiliency for participants in the scale is from $0-100$, the higher the score indicates high resiliency. In present study, score of each factor were reported individually. Validity of the Connor-Davidson Resilience scale was measured with Kobasa hardiness measure $(\mathrm{r}=0.83$, $\mathrm{p}<0.0001)$ and with Stress Scale $(r=-0, p>0.001)$. The reliability of the scale for the whole scale with the approach of internal consistency (Cronbach's alpha) through Test-retest in first stage was 0.89 and the mean score (SD) scale was [52/7 (17.9)] and in the second stage was [52.8 (19.9)] which indicate high Interclass correlation coefficients (0.87). In a study conducted by (Samani, Joukar, \& Sahragard, 2007), the reliability of this scale using Cronbach's alpha coefficient was 0.87 . The drawback to this scale is lake of description of the process of resiliency and lakes of describe the process of implementation and minor divisions and the lack of description in accurate grading (Basim \& Cetin, 2011). Every individual due to their recent feelings were answered the questions. Currently mean score of resiliency is valid just for research goals (Khakpoor \& Mehrafarid, 2012; Shafieezadeh, 2012), however, in foreign researches factors are also addressed (Anderson et al., 2012). Also, Khoshouei in 2009 had done the psychometric scale of Connor-Davidson resiliency in Iran with 4 factors.

Third section, Religious Attitudes Questionnaire that in current study to measure religious attitude we used Serajzadeh's "Muslim Religiosity questionnaire" designed based on Glock and Stark model. This questionnaire has 26 items, which contains of 4 subscale of religion such as beliefs (items from 1 to 7), experiential (items from 8 to 13), consequential (item number 14 to 19), ritual (items from 29 to 26) domains were measured. Belief dimension, are those which are expected to be believed in by a specific religion followers. Based on the 5-point Likert scale every items contain of 5 value degree (strongly agree, agree, interstitial, disagree, and strongly disagree) and the score of 4 to 0 had been allocated for every item but scoring item 7, 141617 and 19 are reversed (0 to 4 ).

The score of the participants in each of these scales, as well as the score of the total score index as the overall, was interpreted as the severity or intensity of general religious attitudes of an individual in that dimension. The higher one's score in a dimension the stronger the severity of the individual's religious attitude in that specific dimension. The same interpretation applies to score in the index overall score. Serajzadeh reported the validity of this questionnaire 0.61 and the reliability of this tool with the Cronbach's alpha coefficients estimated 0.78 .

Forth section, questionnaire of domestic violence is derived from the World Health Organization and it contains of 25 items which covers the physical, sexual and mental domains; physical violence domain has 9 items, sexual violence has 5 items and mental violence domain has 11 items and based on the 5-point Likert scale mode, never; once, twice, five times and more than 5 times; the items are measured. Women who have experienced once to twice violence are placed in mild violence group; those who with 5 times violence experience, are placed 
in-group of moderate violence, those with more than 5 times of violence experience, are placed in severe violence group. And it was assumed the individual under violence has at least one positive answer to each question from physical, sexual and mental violence questionnaire.

Iranian researcher has investigated validity of this questionnaire; also, Cronbach's alpha coefficient of the questionnaire on three different areas of questionnaire was estimated: 92 percent in physical violence, 89 percent in mental violence and 88 percent in sexual violence. It should be noted that, in present study, violence is surveyed in all periods of marriage. This tool was used for identification and selection of research units.

\section{Results}

In terms of demographic characteristic, the highest percentage of age among women under violence were regarding to age category of 20-30 years, 68 individuals (41.2 percent), and then age category of 31-40 years with 65 individuals (39.4 percent). Minimum and maximum age was 20 and 60 years, in orderly. The lowest frequency were regarding to age category of 51-60 year. According to the findings, domestic violence was, in physical violence ( 6 individuals, 3.6 percent), psychiatric violence (51 individuals, 30.9 percent) and a mixture of all kind of violence. Present study indicated that mental violence was more frequent than other type of violence (67.3 percent). The most frequent, 97 women (58.8 percent), had been under domestic violence for the duration of more than 10 years, 51 individuals ( 30.9 percent), had reported 10 to 20 years of domestic violence and 3 individuals (1.8 percent), reported the duration of more than 30 years of domestic violence.

Table 1. Descriptive index survey of religious attitudes and its dimensions based on 100 score rating

\begin{tabular}{lllll}
\hline Variable & Minimum & Maximum & Mean & Standard Deviation \\
\hline Religious Attitude & 48.08 & 96.15 & 76.41 & 9.96 \\
Beliefs Domains & 39.29 & 100 & 93.17 & 11.27 \\
Experiential Domains & 58.33 & 100 & 93 & 9.62 \\
Consequential Domains & 12.50 & 100 & 66.77 & 19.53 \\
Ritual Domains & 0 & 89.29 & 53.53 & 15.22 \\
\hline
\end{tabular}

Mean and standard deviation of religious attitudes was 76.41 99.96 . The results showed that among women under violence, the highest average were in the beliefs domains (93.17) and experiential domains (93) and These results indicated that in more internal dimensions (belief and experiential domain), the majority of cases have higher religious attitude; however, the more objective and social the dimension (ritual and consequences), the lower the scores were (Table 1).

Table 2. Descriptive index survey of resiliency in women under domestic violence

\begin{tabular}{lllll}
\hline Variable & Minimum & Maximum & Mean & Standard deviation \\
\hline Resiliency & 27 & 100 & 68.46 & 15.68 \\
Individual merit & 6.25 & 100 & 68.77 & 18.63 \\
Trusting the instincts & 14.29 & 100 & 64.33 & 18.80 \\
Positive acceptance of changes and having & 20 & 100 & 68.87 & 19.07 \\
secure connections & 0 & 100 & 64.94 & 23.88 \\
Control & 0 & 100 & 84.09 & 20.58 \\
Spirituality & 0 & & & \\
\hline
\end{tabular}

Mean and standard deviation of resilience among the women with domestic violence was $68.46 \pm 15.68$. The results indicate that among women under violence, the highest average was spirituality factor (84.09) (Table 2).

Table 3. Correlation between religious attitude and resiliency in women under domestic violence

\begin{tabular}{lll}
\hline Variable & Religious attitude & \\
\hline Resiliency & Pearson correlation & The probability \\
& 0.24 & P-value $<0.001$ \\
\hline
\end{tabular}

Pearson correlation test result indicates the presence of direct correlation between resiliency and religious 
attitudes, which means the more religious attitudes in an individual; the more resiliency (Table 3).

Table 4. Correlation between religious attitude and resiliency due to the factors in women under domestic violence

\begin{tabular}{|c|c|c|c|c|}
\hline Religious attitude & $\begin{array}{l}\text { Religious } \\
\text { Attitude }\end{array}$ & $\begin{array}{l}\text { Beliefs } \\
\text { Factor }\end{array}$ & $\begin{array}{l}\text { Experiential } \\
\text { Factor }\end{array}$ & $\begin{array}{l}\text { Ritual } \\
\text { Factor }\end{array}$ \\
\hline \multirow{2}{*}{ Resiliency } & $\mathrm{r}=0.24$ & $\mathrm{r}=0.21$ & $\mathrm{r}=0.21$ & $\mathrm{r}=0.24$ \\
\hline & $\mathrm{p}$-value $<0.001$ & $\mathrm{p}$-value $=0.01$ & $\mathrm{p}$-value $=0.01$ & $\mathrm{p}$-value $=0.001$ \\
\hline \multirow{2}{*}{ Individual merit } & $\mathrm{r}=0.18$ & $\mathrm{r}=0.17$ & $\mathrm{r}=0.17$ & $\mathrm{r}=0.21$ \\
\hline & p-value $=0.02$ & p-value $=0.03$ & p-value $=0.03$ & p-value $=0.01$ \\
\hline \multirow{2}{*}{ Trusting the instincts } & $\mathrm{r}=0.11$ & $\mathrm{r}=0.06$ & $\mathrm{r}=0.16$ & $\mathrm{r}=0.15$ \\
\hline & $\mathrm{p}$-value $=0.16$ & p-value $=0.44$ & p-value $=0.04$ & $p$-value $=0.05$ \\
\hline \multirow{2}{*}{$\begin{array}{l}\text { Positive acceptance of changes and having secure } \\
\text { connections }\end{array}$} & $\mathrm{r}=0.22$ & $\mathrm{r}=0.17$ & $\mathrm{r}=0.15$ & $\mathrm{r}=-0.17$ \\
\hline & $\mathrm{p}$-value $=0.01$ & $\mathrm{p}$-value $=0.02$ & $\mathrm{p}$-value $=0.04$ & $\mathrm{p}$-value $=0.03$ \\
\hline \multirow{2}{*}{ Control } & $\mathrm{r}=0.27$ & $\mathrm{r}=0.31$ & $\mathrm{r}=0.21$ & $\mathrm{r}=0.26$ \\
\hline & p-value $<0.01$ & p-value $<0.01$ & $\mathrm{p}$-value $=0.01$ & $\mathrm{p}$-value $<0.001$ \\
\hline
\end{tabular}

Test result of Pearson indicated correlation between resiliency and beliefs, experiential and ritual domains, however, the correlation between religious attitudes and resiliency factors, is not significantly associated with the trusting the instincts. Individual merit factor, positive acceptance of changes and control factors have direct positive correlation with beliefs, experiential and ritual domains. Spiritual factor has a direct positive correlation with all domains of religious attitude; and trusting the instincts factor has direct relation with just the experiential factor (Table 4).

\section{Discussion}

Present study was conducted with the aim of determine the correlation between religious attitudes with resiliency of women under domestic violence who were referred to Health Care Centers of Shahid Beheshti University of Medical Sciences.

The interpretation of this study complies with the results of (Serajzadeh, Shariati Mazinani, \& Saber)'s study (2010) and (Serajzadeh, 2000); and can be the indicator of the true dimensions of religiosity in Iranian people. The present study is consistent with the results of (Hosseinchari \& Mohammadi)'s study (2012); which in religious beliefs dimension or belief domain, mean score was obtained 81.07 (the majority of the cases were girl).

The study result suggests, women experiencing domestic violence, had sufficient religious attitudes and considering the majority of those women (149 individual; 90.3 percent), who were married and had stayed on the domestic relationship and shown compatibility with the domestic violence; the religious attitudes was an effective factor (Brewer-Smyth \& Koeing, 2014; Bryant-Davis \& Wong, 2013; Dueck \& Byron, 2011); studies likewise, indicated that religion can effect on coping with disasters; which considering the victims of violence. The results are consistent with other studies that were conducted in 2012, where 60 percent of the population was religious (Anastasova, 2014).

Results are consistent with Holliman's (2006) study, with the title of "The resilience of women experiencing domestic violence". In this study, women indicated the spirituality as an integral part of their lives and considered it as a coping mechanism. The results of this research are consistent with (Sinha \& Rosenberg)'s study (2013) with the title of "Interventions incident and religion among young people and social violence" and (Fortune, Abugideiri, \& Dratch)'s study (2010); who believe that a religious person can be provided with required strength and courage when facing with a situation very painful and make changes; and knows spirituality and religion factors as a mediator and balanced the effects of chronic social violence.

In (Mahoney\& Tarakeshwar)'s study (2005); the framework of spiritual relationship, can be a good justification for staying or leaving a violent relationship. In present study, 149 women under domestic violence are married ( 90.3 percent), 7 divorced ( 4.2 percent), and 5 have remarried ( 3 percent). In this study, it is mentioned that, in general religion can reduce the risk of experiencing violence however; significant differences between couples in spiritual matters could increase the risk. Inner sense of spiritual support from God can enable victims of 
domestic violence to leave offenders who are insisting on mass, while a sense of commitment to God can encourage a person to stay, despite the heavy cost of violence for her; other findings indicated that membership of some religious groups could facilitate or prevent the outflow of the survivors of the close ties which are to be abused. Religious victims of domestic violence are conservative; they will alter their spiritual expectations of their partners and use their faith as a source of reconciliation with the offender or leave them.

In (Nasir \& Naderi)'s study (2014); among 16- 18 years old girls, average religious attitude were 73.64, which are consistent with the average religious attitude in present study. In (Narimani \& Rostami)'s study (2014) "conducted between mothers with mental retardation problem which can lead to tension, frustration and hopelessness", religious attitude was indicated (70.19 \pm 4.283$)$, which is consistent with the result of the present study. In this study, it is mentioned that religion can enable an individual, to control the tension from the aspect of the Intrapersonal, which will help to accept their responsibilities of their action in conflicts; and from the aspect of interpersonal can make circumstances in which a hopeless individual pay attention to God and make a strong base against problems.

With regard to determination of resilience in women under domestic violence results showed that mean score for resiliency is 68.45 , maximum mean score is related to spirituality factor (84.09). There are no studies related to resiliency of women under domestic violence in Iran up to present date whoever, there are studies, which examined the resiliency among mothers with mentally, retarded child and or sick child (Hagh Ranjbar, Kakavand, Borjali, \& Bermas, 2011; Hussein Qomi \& Salimi Bejestani, 2012).

Present study indicated a relatively high level of resiliency among women under domestic violence, and the seeming paradox of high resiliency despite considerable stress; it is not uncommon (Wilks \& Croom, 2008). In the study conducted by (Shakerinia \& Mohamadpour, 2010), resiliency was considered stress reduction factor and stated that with the element of resiliency can be resisted against the many psychological pressures. Also, in (Benzis \& Mychasiuk)'s study (2009) being female was considered a protective factors and resilience.

Results indicated that maximum mean score related to the phrase "When there is no clear solution to our problems sometimes God or fate can help" is $(\mathrm{M}=3.43)$, "I believe that in any good and bad situation there are convenience" ( $\mathrm{M}=3.29)$, "I prefer to solve my problem myself instead of others take decisions" and the minimum mean score was from the phrase "I like life's challenges" $(\mathrm{M}=2.04)$ and "When I'm under pressure, I do not lose my focus and just think rightfully" $(\mathrm{M}=2.09)$. These results have a close consistent with Anderson et al. study in 2012. Also in this study the mean score of women under domestic violence was reported 74.97, which is in completing consistent with present study. The result of (Shakerinia \& Mohammadpour)'s study (2010), on female nurses also showed mean score of 56.11 for resiliency and 61.41 score for occupational tension; and stated resiliency was a attenuate factor of tension and introduced it as a withstand psychological pressure. Mean score for resiliency in study of (Hagh Ranjbar et al., 2011), was obtained 54 \pm 16.05 . In (Nasir \& Naderi)'s study (2014), resiliency among 16-18 years old girls was reported 61.14.

In connection with determining the correlation between religious attitude with resiliency in women under domestic violence results indicated a statistically significant correlation between resiliency and religious attitude $(\mathrm{p}<0.001, \mathrm{r}=0.24)$. The result of Pearson correlation test between dominations of religious attitude and resiliency indicated direct correlation between resiliencies and beliefs, experiential and ritual areas; this correlation between religious attitude and resiliency factors was insignificant only with trusting the instincts. Individual merit, positive acceptances of changes and having secured connections and control have direct correlation with all dimensions of religious attitude; and trusting the instincts had direct relation with only experiential factor.

The results of current study are in consistent with the (Ward, Mengesha, \& Issa)'s study (2014) of "African elderly women who live with depression and their coping behaviors". These Women, who suffered from depression, had the history of physical and sexual or psychological abuse. Adaptive behaviors in these women were included religious practices and resiliency. These women believed that adaptive behaviors were bulwark against psychiatric disorders. They chose religious coping and resiliency as their core of coping strategies (culturally acceptable strategies). Religious coping were: believing in God, praying, Bible reading and communication with priests and participation in religious activities of churches. These women believed, religious adaptation decreased their depression signs. Resiliency is another main core of adaptation strategies. These women believed resiliency kept them strong gave them the benefit of living in the moment and having positive attitude, which could be protective.

Fleming and ledogar's study (2008), with the title of "Resiliency and Innate spirituality" is also in consistent with present study. In this study religious attitude was reported to be effective scores of prevention and liberation form alcohol abuse, substance abuse, suicide and Behavioral disorders. These finding are in consistent with 
(Zauszniewski, Bekhet, \& Suresky)'s study (2010). This study stated that being religious could help with adapting to conditions, and implied religion as an individual factor of resiliency.

Also, in a study conducted by Wu (2011), role of religion in resiliency was confirmed. Participants were family members of violence victims or crimes such as actual assault or attempted physical assaults; who were referred to support for victims of criminal offenses associations. This study indicated 80 percent of participants were sort of religious who received social supports through religion, affecting their life events and their point of view. Also it is expressed; resiliency would increase, through individual characteristics such as self-esteem, self-confidence and supportive scores (such as religious activities).

In (Ahmadi, Sheikh, \& Sarabandi)'s study (2012); also confirmed the positive correlation ( $\mathrm{r}=0.89$ ), between devotion to the God in safety and resiliency. In (Shamohamadi \& Balali)'s study (2014), among divorced women; (Annalakshmi and Abeer)'s study (2011); (Keshavarzi \& yousefi 2011; Hamid, Keikhosravani, Babamiri, \& Dehgani, 2012); as well confirmed the positive correlation between spiritual leanings and its components and resiliency; which are in consistent with present study.

It can be said that religion is not just a path for emotional health but, it can be effective in personal chaos, therefor-religious attitude could give support and personal strength, which is very effective on their compatibility. These studies are implied that providing supportive factors (such as religion and spirituality), in order to enhance mental health and spiritual intelligence, would result in increase of resiliency.

\section{Conclusion}

According to the findings indicating correlation between religious attitude and resiliency in women under domestic violence, and also that, women who had higher religious attitude had more resiliency; therefore it is recommended to pay more attention to the resilience of women experiencing domestic violence and its effecting factors, specially religious attitude, considering the beliefs and cultural aspects of Iranian women and given the role of religion in feel of strength, hope, the feel of belonging and safety. Spiritual and religious beliefs provides, hope and the sense of mastery over fate; and if a believer, fully trust in God, could grow in any difficult situations.

Because of the concept of domestic violence, it seems some cases were cautious in the provision of information. The researcher tried to overcome this limitation of the use of communication skills. It is recommended in future studies review the adaptive behaviors in women experiencing domestic violence, the relation between coping strategies of stress (effecting Problem-focused, Emotion-focused strategies), in women under domestic violence and empowering and resiliency in them.

\section{Acknowledgements}

This article is the result from postgraduate thesis, which was conducted in Shahid Beheshti University of Medical Sciences. The authors would like to express their appreciation to the participants and all those who contributed in this research, who without their cooperation, this study would not be possible.

\section{Competing Interests Statement}

The authors declare that there is no conflict of interests regarding the publication of this paper.

\section{References}

Aghakhani, N., Eftekhari, A., Zare Kheirabad, A., \& Mousavi, E. (2012). Study of the effect of various domestic violence against women and related factors in women who referred to the Forensic Medical Center in Urmia city-Iran 2012-2013. IJFM, 18(2), 69-78.

Ahmadi, K., Sheikh, M., \& Sarabandi, H. (2012). The Role of Attachment to God in Resilience and Mental Health of the parents of Trainable Mentally Retarded Children medical science \& Health service. Thesis. Research Psychological Health, 6(1), 1-9.

Alokan, F. B. (2013). Domestic violence against women: A family menace. Journal of marriage and Family, 57(2), 283-294.

Anastasova, R. A. (2014). Understanding the Role of Religion in Coping after Trauma: Resilience, Post-traumatic Growth and Difference in Coping Mechanisms. Thesis.

Annalakshmi, N., \& Abeer, M. (2011). Islamic worldview, religious personality and resilience among Muslim adolescent students in India. Europe's Journal of Psychology, 7(4), 716-738. http://dx.doi.org/10.5964/ejop. v7i4.161

Bagherzadeh, R., Kheshavarz, T., Sharif, F., Dehbashi, S., Tabatabaee, M. D. H. R., \& Heidari, M. (2009). 
Demographic characteristics of women with domestic violence during pregnancy. Scientific Journal of Hamadan Nursing \& Midwifery Faculty, 16(2), 5-15.

Basim, H. N., \& Cetin, F. (2011). The reliability and validity of the Resilience Scale for Adults-Turkish Version. Turk Psikiyatri Dergisi, 22(2), 104-114.

Bauman, E. M., Haaga, D. A., Kaltman, S., \& Dutton, M. A. (2012). Measuring Social Support in Battered Women Factor Structure of the Interpersonal Support Evaluation List (ISEL). Violence against women, 18(1), 30-43. http://dx.doi.org/10.1177/1077801212436523

Benzies, K., \& Mychasiuk, R. (2009). Fostering family resiliency: A review of the key protective factors. Child \& Family Social Work, 14(1), 103-114. http://dx.doi.org/10.1111/j.1365-2206.2008.00586.x

Brewer-Smyth, K., \& Koenig, H. G. (2014). Could spirituality and religion promote stress resilience in survivors of childhood trauma? Issues in mental health nursing, 35(4), 251-256. http://dx.doi.org/10.3109/01612840. 2013.873101

Bryant-Davis, T., \& Wong, E. C. (2013). Faith to move mountains: Religious coping, spirituality, and interpersonal trauma recovery. American Psychologist, 68(8), 675. http://dx.doi.org/10.1037/a0034380

Chiswick, B. R., \& Mirtcheva, D. M. (2013). Religion and child health: Religious affiliation, importance, and attendance and health status among American youth. Journal of family and economic issues, 34(1), 120-140. http://dx.doi.org/10.1007/s10834-012-9312-5

Clark, C. J., Bloom, D. E., Hill, A. G., \& Silverman, J. G. (2009). Prevalence estimate of intimate partner violence in Jordan. Eastern Mediterranean Health Journal, (15), 880-889.

Coker, A. L., Smith, P. H., Whitaker, D. J., Le, B., Crawford, T. N., \& Flerx, V. C. (2012). Effect of an in-clinic IPV advocate intervention to increase help seeking, reduce violence, and improve well-being. Violence against women, 18(1), 118-131. http://dx.doi.org/10.1177/1077801212437908

Connor, K. M., \& Davidson, J. R. (2003). Development of a new resilience scale: The Connor-Davidson resilience scale (CD-RISC). Depression and anxiety, 18(2), 76-82. http://dx.doi.org/10.1002/da.10113

Davis, R. (2010). Domestic violence-related deaths. Journal of aggression, conflict and peace research, 2(2), 44-52. http://dx.doi.org/10.5042/jacpr.2010.0141

Dolatian, M., Hesami, K., Shams, J., \& Alavi Majd, H. (2007). Investigate the relationship between breastfeeding duration and effects of domestic violence. Journal of Nursing, 18(61), 20-27.

Dolatian, M., Zahiroddin, A., Velaie, N., \& Majd, H. A. (2012). Evaluation of prevalence of domestic violence and its role on mental health. Pajoohandeh Journal, 16(6), 277-283.

Dueck, A., \& Byron, K. (2011). Community, spiritual traditions, and disasters in collective societies. Journal of Psychology and Theology, 39(3), 244.

Faramarzi, S., Abedi, M. R., \& Karimi, M. (2013). The Relationship between Coping Styles and Adolescents' Depression, 3(2), 17-27.

Fleming, J., \& Ledogar, R. J. (2008). Resilience and indigenous spirituality: A literature review. Pimatisiwin, $6(2), 47-64$.

Fortune, M., Abugideiri, S. E., \& Dratch, M. (2010). A commentary on religion and domestic violence. Domestic Violence: Intersectionality and Culturally Competent Practice, 318.

Frías, S. M. (2013). Strategies and help-seeking behavior among Mexican women experiencing partner violence. Violence against women, 19(1), 24-49. http://dx.doi.org/10.1177/1077801212475334

Hagh Ranjbar, F., Kakavand, A., Borjali, A., \& Bermas, H. (2011). Resilience and quality of life of mothers of children with mental retardation. Journal of Health Psychology, 6(2), 45-56.

Hajian, S., Vakilian, K., Najm-abadi, K. M., Hajian, P., \& Jalalian, M. (2014). Violence against women by their intimate partners in Shahroud in northeastern region of Iran. Global journal of health science, 6(3), 117-130. http://dx.doi.org/10.5539/gjhs.v6n3p117

Hamid, N., Babamiri, M., \& Dehghani, M. (2012). The relationship between mental healths, spiritual intelligence with resiliency in student of Kermanshah University of Medical Sciences. Jentashapir Journal of Health Research, 3(2), 331-338.

Holliman, A. (2006). Against ALL odds: Resilience in women victim of intimate partner violence. Proceeding of 
The National Conference on Undergraduate Research, 6-8, 2810-2814.

Hosseinchari, M., \& Mohammadi, M. (2011). Predicting psychological resilience based on religious beliefs in urban and rural university students. Contemporary Psychology, 6(2), 45-56.

Husseini Qomi, T., \& Salimi Bejestani, H. (2012). The Relationship between Religious Orientation and Endurance among the Mothers Having Ailing Children Ravanshenasi-va-Din, 4(3), 69-82.

Jain, S., Buka, S. L., Subramanian, S. V., \& Molnar, B. E. (2012). Protective factors for youth exposed to violence role of developmental assets in building emotional resilience. Youth Violence and Juvenile Justice, 10(1), 107-129. http://dx.doi.org/10.1177/1541204011424735

Jowkar, B., \& Noorafshan, L. (2013). Relationship between imaginary audience and personal fable with resilience. International Journal of Behavioral Sciences, 7(3), 207-214.

Kaplan, H. I., \& Sadock, B. J. (2007). Synopsis of psychiatry: Behavioral sciences clinical psychiatry (10th ed.).

Karami, M. (2015). The Relationship between spiritual trends, Organizational Commitment and Resilience among Nurses Who work in Hospitals of Shiraz University of Medical Science. The international Branch of Shahid Beheshti University of Medical Sciences \& Health Services.Thesis for MS degree In Nursing Management-Medical Surgical.

Karimi Khoshhal, M. (2014). The relationship between domestic violence and social support vin early cessation ofbreastfeeding mothers in centers health services lahijan city in 2014 (Shahid Beheshti University of Medical Science and Health Services, Faculty of Nursing and Midwifery. Ms Thesis).

Keshavarzi, S., \& Yousefi, F. (2012). The Relationship between Emotional Intelligence, Spiritual Intelligence and Resilience. Journal of Psychology, 16(3), 299-318.

Khakpour, M., \& Mehrafarid, M. (2013). Comparison of Mental Disorders and Resiliency in Couples withNormal \& Exceptional Children (First Child) in Faruj city. Journal of North Khorasan University of Medical Sciences, 4(4), 571-583.

Khoshouei, M. S. (2009). Psychometric evaluation of the Connor-Davidson Resilience Scale (CD-RISC) using Iranian students. International Journal of Testing, 9(1), 60-66. http://dx.doi.org/10.1080/153050509 02733471

Latifi, M., Taghdisi, M., Estebsari, F., Rahimi, Z., \& Joveini, H. (2013). Survey of Wife Abuse and Influencing Social Factors Incidence of Domestic Violence in Tehranian Families, 3(1), 11-17.

Mahoney, A., \& Tarakeshwar, N. (2005). Religion's role in marriage and parenting in daily life and during family crises. Handbook of the psychology of religion and spirituality, 177-195.

Mohtashami, J., Yaghmaei, F., Jafari, A., Alavi Majd, H., \& Ahmadi, A. (2014). Related factors to coping with domestic violence in women who refer to Forensic Medicine Centers in Tehran. Journal of Health Promotion Management, 3(2), 54-64.

Narimani, M., \& Rostami, M. (2014). Role of Religious attitudes, Spiritual Well-Being and social support in predicting the life satisfaction in mothers of mental retardation children. Islam and Health Journal, 1(3), 41-49.

Nasiri, M., \& Naderi, F. (2014). The Relationship Religious Beliefes and Resilience with optimism in female high school students. Journal of Women and the culture, 5(19), 59-47.

Payne, D., \& Wermeling, L. (2009). Domestic violence and the female victim: The real reason women stay. Journal of Multicultural, Gender and Minority Studies, 3(1), 1-6.

Perez, S., Johnson, D. M., \& Wright, C. V. (2012). The attenuating effect of empowerment on IPV-related PTSD symptoms in battered women living in domestic violence shelters. Violence against Women, 18(1), 102-117. http://dx.doi.org/10.1177/1077801212437348

Rahnavardi, M. (2014). Relationship between domestic violence and suicidal thought on women referred to Rasht city health medical center and the family court in 2014 (Shahid Beheshti University of Medical Science and Health Services. Faculty of Nursing and Midwifery. Ms Thesis.)

Rajabi, M., Saremi, A., \& Hossein Bayazi, M. (2012). The Relationship between religious coping patternsm mental health and happiness. Developmental Psychology: 5th International Conference of Cognitive Science, 7-9. Tehran-Iran.

Rassouli, M., Yaghmaie, F., Alavi Majd, H., \& Saeedolzakerin, M. (2009). Development and Psychometrics of 
"Institutionalized Adolescents Spiritual Coping Scale". Iranian Journal of Psychiatry and Clinical Psychology, 15(1), 25-32.

Rezaei, A. (2014). Testing and developing resilience model in adolescents with cancer the international branch of shahid Beheshti University of medical science \& Health service. Thesis.

Sadeghi Fsayy, S. (2011). Domestic violence and women's strategies to cope with it (qualitative study). Journal of social issues, 1(1), 107-142.

Samani, S., Joukar, B., \& Sahragard, N. (2007). Effects of resilience on mental health and life satisfaction. Iranian Journal of Psychiatry and Clinical Psychology, 13(3), 290-295.

Sarajzadeh, S., Shariati Mazinani, S., \& Saber, S. (2010). Relationship between Degrees an Types of Religiosity and Social Tolerance. Journal of Social Sciences (Biannual), 109-142.

Serajzadeh, S. (2000). A religious attitudes and behaviors of adolescents in Tehran and its implications for the theory of secularization. Journal of Research profile, 7(8), 105-120.

Seyed Mahmoudi, S., Rahimi, C., \& Mohamadi, N. (2011). The Influential Determinants of resilience in people with trauma. Research in Clinical Psychology, 1(1), 5-14.

Shafieezadeh, R. (2012). The relationship between resilience and the big five personality factors. Knowledge \& Research in Applied Psychology, 13(3), 95-102.

Shakerinia, I., \& Mohammadpour, M. (2010). Relationship between job stress and resiliency with occupational burnout among nurses. J Kermanshah University of Medical Science, 14(2), 161-169.

Shamohammadi, M., \& Balali, T. (2014). The relationship between religious attitude adjustments after divorce divorced women. Regional Conference on Pathology published in the divorce phenomenon.

Sinha, J. W., \& Rosenberg, L. B. (2013). A critical review of trauma interventions and religion among youth exposed to community violence. Journal of Social Service Research, 39(4), 436-454. http://dx.doi.org/10. 1080/01488376.2012.730907

Sobhani-Herfati, R. (2012). An investigation of the relationship between attachment to God and resilience with meaningful life among students. JSR, 13(49), 75-85.

Soleiman Ekhtiari, Y., \& Ahmadi, B. (2011). A review of studies about efficacy of public health interventions for prevention of domestic violence against women. Social Welfare Quarterly, 11(40), 237-257.

Vosoogh, M., \& Forouzesh, M. (2013). Demographic Study of the Wife Abuse Victims Referred to Zanjan Legal Medicine Center in 2010. IJFM, 19(4), 193-204.

Ward, E. C., Mengesha, M., \& Issa, F. (2014). Older African American women's lived experiences with depression and coping behaviours. Journal of Psychiatric and Mental health nursing, 21(1), 46-59. http://dx.doi.org/10.1111/jpm.12046

Wu, H. C. (2011). The protective effects of resilience and hope on quality of life of the families coping with the criminal traumatisation of one of its members. Journal of clinical nursing, 20(13-14), 1906-1915. http://dx.doi.org/10.1111/j.1365-2702.2010.03664.x

Yousefi N. (2013). The impact and meaning of religion-based cognitive therapy in reducing symptoms of depression, anxiety and aggressiveness students. Culture Counseling and Psychotherapy, 3(10), 137-158.

Zauszniewski, J. A., Bekhet, A. K., \& Suresky, M. J. (2010). Resilience in family members of persons with serious mental illness. Nursing Clinics of North America, 45(4), 613-626. http://dx.doi.org/10.1016 /j.cnur.2010.06.007

Zolkoski, S. M., \& Bullock, L. M. (2012). Resilience in children and youth: A review. Children and Youth Services Review, 34(12), 2295-2303. http://dx.doi.org/10.1016/j.childyouth.2012.08.009

\section{Copyrights}

Copyright for this article is retained by the author(s), with first publication rights granted to the journal.

This is an open-access article distributed under the terms and conditions of the Creative Commons Attribution license (http://creativecommons.org/licenses/by/4.0/). 